\title{
BUDIDAYA DAN PEMANFAATAN TANAMAN OBAMA (OKRA BANYAK MANFAAT) MENJADI INKUBATI BISNIS DI SMPN 20 SURABAYA
}

\author{
M. Hasan Abdullah ${ }^{1}$, Ampar Jaya Suwondo ${ }^{2}$, Dyah Puspita IBSW ${ }^{3}$ \\ ${ }^{1}$ Universitas Wijaya Putra \\ ${ }^{2}$ Universitas Wijaya Putra \\ ${ }^{3}$ Universitas Wijaya Putra
}

mhasanabdullah@uwp.ac.id, amparj@yahoo.co.id,dyahpuspitaibsw1998@gmail.com

\begin{abstract}
Abstrak
Mitra pada Program Pemberdayaan Masyarakat (PPM) ini adalah Tunas Hijau, sebuah kegiatan ekstra kulikuler di SMPN 20 Surabaya. Tunas Hijau mempunyai misi untuk mengembangkan kompetensi siswa di bidang ecopreneurship. Salah satu obyek yang menjadi produk dalam pengembangan ecopreneur adalah budidaya dan pengolahan tanaman Okra. Namun untuk mewujudkan misi tersebut mitra menghadapi beberapa kendala. Mitra belum mempunyai pengetahuan dalam membentuk inkubator bisnis serta menjalanan inkubator bisnis untuk meningkatkan kompetensi ecopreneur pada siswa sekolah. Mitra juga belum mempunyai keterampilan untuk membudiyakan tanaman Okra dan mengolah menjadi produk yang menarik bagi konsumen. Tujuan dari program pengabdian ini adalah pertama, untuk mengembangkan model inkubator bisnis Tunas Hijau sebagai model pembelajaran dan pelatihan kompetensi kewirausahaan pada siswa. Kedua, meningkatkan kemampuan mitra dalam membudidayakan dan mengolah tanaman Okra menjadi produk yang sukses menarik konsumen. Metode yang digunakan yaitu pelatihan dan pendampingan pada mitra terkait hal bagaimana merancang inkubator bisnis serta evaluasi untuk mengetahui efektivitas model inkubator bisnis di Tunas Hijau serta cara membudidayakan dan mengolah tanaman Okra menjadi produk bernilai jual. Hasil dari kegiatan ini mitra mempunyai kompetensi merancang model inkubator bisnis serta keterampilan membudidayakan dan menghasilkan produk yang bersaing berbasis Okra.
\end{abstract}

Kata Kunci : Ecopreneur, Okra, Tunas Hijau

\section{PENDAHULUAN}

Mitra pada Program Pemberdayaan Masyarakat (PPM) ini adalah adalah Tunas Hijau, sebuah ekskul (ekstra kulikuler) di SMPN 20 Surabaya. Tunas Hijau mempunyai misi untuk mengembangkan kompetensi siswa di bidang ecopreneurship melalui sebuah inkubator bisnis. Sebagaimana pengertian menurut National Business Incubator Association (NBIA), bahwa inkubator bisnis merupakan proses dukungan bisnis yang dapat mempercepat keberhasilan pengembangan startup dan perusahaan pemula dengan menyediakan berbagai sumber daya dan layanan yang diperlukan kepada para pengusaha. Layanan ini biasanya dikembangkan atau diatur oleh manajemen inkubator dan ditawarkan baik dalam inkubator bisnis itu sendiri dan melalui jaringan yang dimiliki oleh inkubator bisnis. Inkubator bisnis dapat memberikan dampak kepada minat siswa untuk berwirausaha (Mayasari, Liliana, \& Seto, 2019). 
Inkubator bisnis biasanya memberikan program kepada pengusaha pemula (early stage) atau startup, yang didesain untuk membina dan mempercepat keberhasilan pengembangan bisnis melalui rangkaian program permodalan yang diikuti oleh dukungan kemitraan atau pembinaan elemen bisnis lainnya dengan tujuan menjadikan usaha tersebut menjadi perusahaan yang profitable, memiliki pengelolaan organisasi dan keuangan yang benar, serta menjadi perusahaan yang sustainable, hingga akhirnya memiliki dampak positif bagi masyarakat.

Berdasarkan hasil observasi dan wawancara dengan calon mitra, beberapa hal dipandang perlu untuk dilakukan pengembangan kegiatan pada mitra terutama terkait dengan perencanaan model bisnis ecopreneur. Salah satu obyek yang menjadi produk dalam pengembangan ecopreneur adalah budidaya dan pengolahan tanaman Okra. Tanaman Okra mempunyai banyak sekali manfaat. Tunas Hijau mempunyai lahan yang cukup luas yang belum dimanfaatkan serta sumber daya manusia yang mendukung. Tunas Hijau SMPN 20 Surabaya mempunyai beberapa pembina yang diambil dari guru di sekolah tersebut. Gambar 1 menunjukkan situasi mitra di SMPN 20.

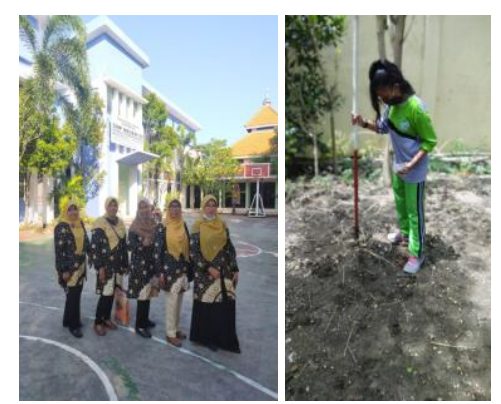

Gambar 1. Foto para pembina kegiatan Tunas Hijau dan salah satu lahan kosong di SMPN 20 Surabaya

Tunas Hijau sebagai salah satu ekstra kulikuler yang diakui oleh departemen Pendidikan dan Kebudayaan, mempunyai tujuan untuk menciptakan semangat ecopreneur di lingkungan sekolah. Dengan sumberdaya yang dimiliki saat ini, Tunas Hijau belum mempunyai sebuah gambaran tentang model bisnis seperti apa dan bagaimana membuat produk olahan yang bernilai jual dari tanaman Okra yang pernah dikembangkan di sekolah. BMC (Business Model Canvas) merupakan salah satu metode yang dapat digunakan untuk merancang sebuah bisnis. Perancangan model bisnis dapat mempertimbangkan kondisi saat ini dan analisis SWOT pada UKM (Aziz, Wulandari, \& Sagita, 2018).

Tunas Hijau berdiri sejak tahun 2012 dengan jumlah anggota 64 siswa. Kegiatan ini dibimbing oleh para guru yang telah ditunjuk oleh kepala sekolah. Bidang kegiatan Tunas Hijau adalah bergerak di bidang sosial, ekonomi dan lingkungan hidup. Saat ini Tunas Hijau sedang mengembangkan budidaya tanaman Okra. Dimana tanaman ini mempunyai banyak manfaat, namun belum banyak masyarakat yang mengetahuinya (Gustiawan, Herawati, \& Noverta, 2018).

Buah Okra memiliki kandungan gizi yang baik dan berkhasiat untuk obat (Fa'izah, 2020). Okra mengandung banyak serat dan berbagai gizi yang bermanfaat bagi kesehatan. Dalam $100 \mathrm{~g}$ buah Okra muda terkandung $90 \mathrm{~g}$ air, $1 \mathrm{~g}$ serat, $70-90 \mathrm{mg}$ kalsium dengan total energi $145 \mathrm{~kJ}$ (Ikrawati \& Rokhmah, 2016). Dengan berbagai zat gizi yang dikandungnya, mengkonsumsi Okra diyakini dapat mencegah anemia, mengurangi risiko kanker, menurunkan kolesterol, menguatkan tulang dan melancarkan pencernaan. Buah Okra juga bisa sebagai obat diabetes (Administrator, cara mengolah okra menjadi obat diabetes, 2017). Dengan demikian, peluang mengusahakan okra sangat terbuka lebar. Namun, kurangnya informasi mengenai tanaman ini menyebabkan Okra belum ditanam secara luas.

Tunas Hijau belum mempunyai sistem pembibitan dan pengembangan tanaman Okra secara modern. Okra memiliki beberapa varietas dan memerlukan perlakuan pupuk yang tepat (Barus, 2016). Saat ini percobaan penanaman dilakukan di pekarangan rumah warga, meski lahan yang ada di SMPN 20 masih cukup luas. Pengolahan hasil tanaman Okra belum bisa maksimal karena keterbatasan bahan. Produk olahan Okra baru didistribusikan di lingkungan sekolah dan warga sekitar.

Mengacu kepada Analisis Situasi yag ada, maka permasalahan mitra yang ada pada dua aspek yakni aspek manajemen dan aspek produksi. Mitra mempunyai peluang dalam mengembangkan tanaman multi khasiat Okra ini. Potensi yang 
dimiliki mitra adalah lahan yang cukup luas dan sumberdaya manusia yaitu pembimbing serta murid yang menjadi anggota Tunas Hijau. Namun, mitra belum mempunyai tujuan jangka panjang dan strategi untuk pengembangan ke depan.

Pada aspek manajemen, mitra belum mempunyai lembaga sebagai inkubator bisnis dan model pembelajaran untuk meningkatkan kompetensi ecopreneur pada siswa sekolah. Pembina yang ada belum dibekali dengan keterampilan dalam mendesain model inkubator bisnis berbasis ecopreneur. Mereka juga tidak mempunyai manual book atau perangkat sebagai media pembelajaran bagi siswa sekolah. Sehingga misi untuk membentuk semangat ecopreneur tidak bisa dilakukan secara maksimal. Untuk itu perlu adanya sebuah konsep atau model bisnis yang cocok yang bisa dijadikan pedoman dan pembelajaran bagi pembina Tunas Hijau.

Pada aspek produksi, saat ini hasil olahan tanaman Okra hanya didistribusikan di lingkungan sekolah dan warga sekitar. Pengolahan dilakukan di rumah salah satu anggota, sehingga hasil produksinya terbatas. Bahan untuk bibit belum bisa diproduksi sendiri. Bibit diperoleh dengan membeli secara online. Percobaan persemaian pernah dilakukan di lahan sekolah dengan cara menanam biji secara langsung. Hasilnya, tanaman tidak dapat tumbuh secara baik dan akhirnya mati karena hama dan perawatan yang tidak tepat. Hal ini karena tanaman Okra masih ditanam secara tradisional (Administrator, teknik penanaman okra serta teknik dan metode pengelolaan lapangan, 2020). Okra dapat tumbuh dengan baik pada suhu tanah 28$30^{\circ} \mathrm{C}$. Okra lebih tahan terhadap tanah kering namun akan mengalami stress pada genangan air (Simanjuntak \& Gultom, 2018).

Hasil olahan Okra belum diproduksi secara masif karena keterbatasan alat dan bahan pendukung. Dengan adanya PPM diharapkan kegiatan ini dapat menjadikan tanaman Okra menjadi sebuah inkubati bisnis bagi kegiatan ekstra Tunas Hijau di SMPN 20 serta menjadi sarana pembelajaran siswa. Hal ini perlu upaya untuk pengembangan Okra yang meliputi pembibitan dan pemeliharaan, pengolahan hasil tanaman Okra, serta distribusi dan pemasaran olahan Okra.
Maka melalui program ini, tim pengabdian masyarakat yang terdiri dari dosen dan mahasiswa berupaya untuk membantu mitra dalam memberikan solusi agar dapat mencapai tujuannya. Beberapa tujuan yang hendak dicapai diantaranya untuk memberikan solusi pada permasalahan manajemen dan produksi. Pada sisi manajemen, mitra diharapkan sudah mempunyai perencanaan inkubator bisnis serta dapat melakukan evaluasi untuk mengetahui efektivitas model inkubator bisnis dalam meningkatkan kompetensi ecopreneur pada siswa sekolah. Pada masalah produksi, mitra mempunyai pengetahuan dan ketrampilan membudiyakan tanaman Okra dan mengolah menjadi produk yang menarik bagi konsumen. Keterampilan dalam pembibitan, pemeliharaan dan pengolahan hasil Okra serta ditunjang dengan keterampilan manajemen yang baik akan dapat mewujudkan sebuah bisnis ecopreneur yang sukses.

\section{METODE}

Metode pelaksanaan kegiatan meliputi tahapan atau langkah-langkah dalam melaksanakan solusi yang ditawarkan. Solusi yang ditawarkan berdasarkan pada hasil analisis situas pada mitra yang dilakukan dengan wawancara dan observasi. Tahap ini dilakukan untuk menentukan permasalahan dan solusi yang tepat dan disepakati oleh mitra. Pelaksanaan program dimulai pada bulan Juli sampai dengan Desember 2021. Tahapan meliputi pelatihan, pendampingan dan evaluasi.

a. Tahap pelatihan.

Pada tahap ini mitra diberikan pelatihan membuat dan mengembangkan Model Business Canvas (BMC), struktur bisnis dan rencana bisnis berbasis ecopreneur. Memberikan pelatihan merancang konsep model pengajaran inkubator bisnis berbasis ecopreneur untuk menumbuhkan jiwa ecopreneurship kepada siswa. Memberikan pelatihan cara pembibitan Okra dengan sistem rumah bibit (mini greenhouse) dan penanaman dengan menggunakan sistem baglog dan tertutup agar tidak mudah terkena hama (Administrator, budidaya okra dalam pot polybag, 2020). Memberikan keterampilan tentang produk olahan Okra yang Marketable. Memberikan pelatihan tentang konsep $4 \mathrm{P}$ (product, price, place, 
promotion). Menggunakan media pemasaran secara on line melalui toko online dan media sosial IG atau instagram.

b. Tahap pendampingan.

Tahap ini dilakukan agar pelaksanaan kongkret dari solusi yang telah direncanakan sesuai dengan terget luaran yang ditentukan. Pendampingan dilakukan pada proses pelatihan manajemen dan produksi. Pendampingan dilakukan selama program ini berlangsung sampai dengan selesai.

c. Tahap evaluasi.

Tahap ini dilakukan untuk melihat hasil pada penerapan solusi. Jika hasil penerapan tidak sesuai dengan target luaran maka perlu dilakukan perbaikan atau penetapan alternatif solusi.

Sebagai penunjang keberlanjutan program ini maka perlu keterlibatkan dari beberapa pihak. Tidak hanya mitra Tunas Hijau sebagai produsen, namun masyarakat sebagai konsumen harus diberikan edukasi dari manfaat produk hasil olahan Okra. Masyarakat akan memberikan feedback positif berupa hasil penjualan dan customer need sebagai masukan untuk peningkatan dan pengembangan produk. Manajemen sekolah juga merupakan bagian yang sangat penting dalam mendukung keberlangsungan program ini. Melalui inkubator bisnis siswa dapat belajar serta aktif dalam kegiatan. Siswa akan termotivasi dengan pembelajaran secara langsung (praktek bisnis). Manajemen sekolah dapat memberikan ekosistem yang baik bagi keberlangsungsn bisnis serta mendapatkan timbal balik positif dengan adanya kegiatan pembelajaran bisnis.

\section{HASIL DAN PEMBAHASAN}

\section{Pelatihan budidaya okra dan inkubator bisnis.}

Pelatihan pada program pengabdiaan ini dilakukan secara daring dan luring. Adanya pemberlakuan PPKM maka perlu dilakukan penyesuaian metode dalam pelatihan atau workshop. Pelatihan secara daring dilakukan melalui media zoom bersama pembina dan siswa yang tegabung dalam Tunas Hijau (Gambar 2). Peserta diberikan materi terkait bagaimana budidaya tanaman Okra secara baik. Peserta mampu untuk memilih benih yang baik, cara penanaman, perawatan sampai pada pengolahan produk-produk yang marketable berbahan buah Okra. Untuk mendukung budidaya Okra, tim membuatkan greenhouse di halaman belakang sekolah. Greenhouse ini nantinya akan digunakan untuk melakukan penyemaian tanaman Okra dan juga tanaman lain yang bermanfaat.

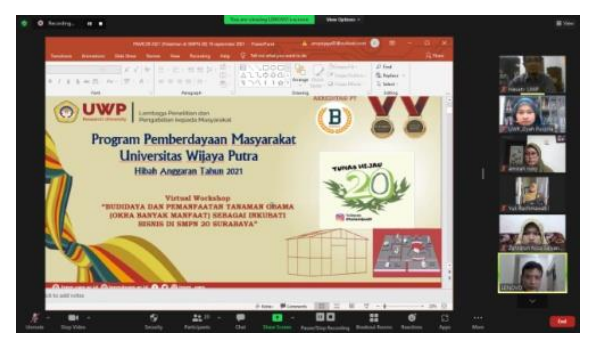

Gambar 2. Pelaksanaan Virtual workshop

Untuk mengetahui tingkat pemahaman peserta, tim melakukan pre-test dan post-test melalui link pada googleform. Dari googleform dapat diketahui secara langsung hasil nilai peserta. Dari hasil nilai dapat diketahui bahwa sebagian besar peserta sudah mempunyai pengetahuan tentang penanaman Okra. Namun masih minim dalam perawatan tanaman. Untuk peserta dari guru atau pembina, keterampilan tentang bisnis model dan perancangan inkubator masih kurang (rata-rata di bawah 60). Bentuk pre-test dan post-test seperti terlihat pada Gambar 3.

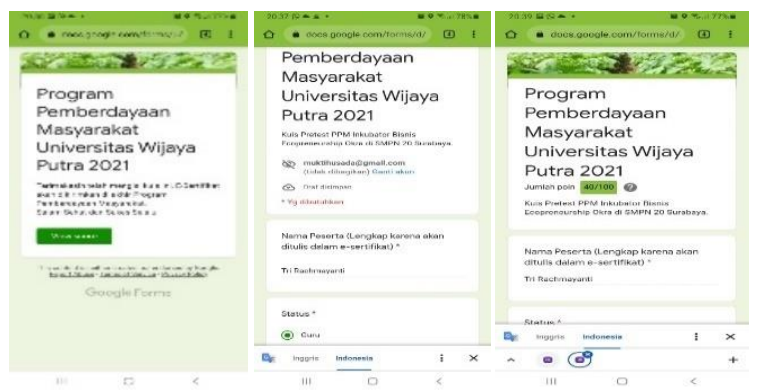

Gambar 3. Pretest dan posttest menggunakan perangkat google form

Selain itu, peserta juga diberikan pelatihan bagaimana membuat model bisnis dan merancang inkubator bisnis di sekolah. Peserta dikenalkan dengan BMC (Bussiness Model Canvas) dan tahapan dalam membuat sebuah inkubator bisnis. 
Pelatihan model bisnis ini diikuti oleh para pembina Tunas Hijau yang sekaligus guru di SMPN 20 Surabaya. Mitra juga difasilitasi dengan greenhouse. Greenhouse dibuat dari bahan yang ringan, kuat dan anti karat. Atap ditutup dengan plastik UV (ultraviolet) yang berfungsi untuk mengurangi radiasi sinar UV yang terlalu tinggi yang dapat menyebabkan tanaman menjadi layu dan mati. Plastik juga berfungsi untuk mengurangi curah hujan yang tinggi. Gambar 4 menunjukkan greenhouse yang telah dibangun dan sudah pada tahap akhir.

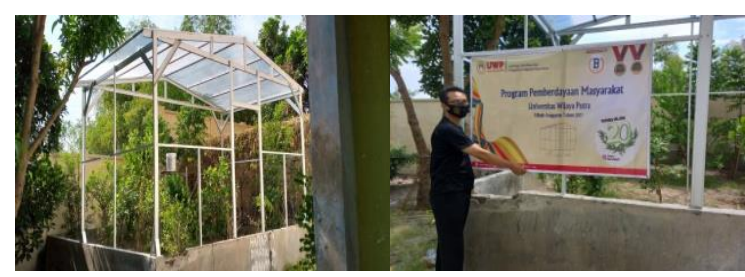

Gambar 4. Pembuatan greenhouse

Mitra pengabdian diberikan pelatihan cara mengolah buah Okra agar bisa menjadi produk yang bernilai. Salah satu pemanfaatannya yaitu dengan mengambil getah buah Okra untuk menjadi Pudding yang lezat. Pudding ini banyak mengandung serat sehingga baik untuk tubuh dan dapat dicampur untuk membuat makanan lainnya seperti sup dan mie (Fa'izah, 2020).

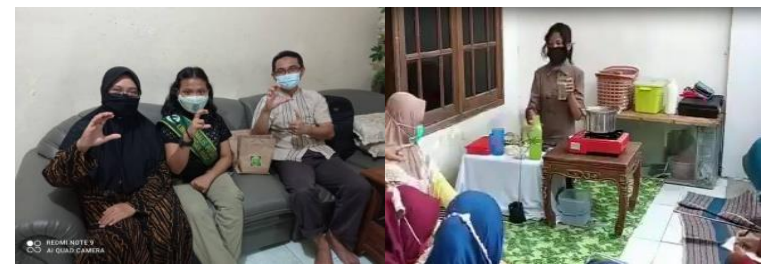

Gambar 5. Kegiatan pelatihan pembuatan produk Okra bersama tim dan warga sekitar

\section{Pendampingan budidaya okra dan inkubator bisnis.}

Pendampingan dilakukan pada mitra saat perancangan bisnis model dan pembentukan inkubator bisnis ecopreneur. Pembina diberikan kerangka penyusunan BMC yang masih kosong untuk diisi. Hal ini untuk melengkapi pelatihan yang telah diikuti secara daring sebelumnya. Gambar 6 merupakan kerangka untuk menyusun bisnis model yang akan diterapkan pada mitra.

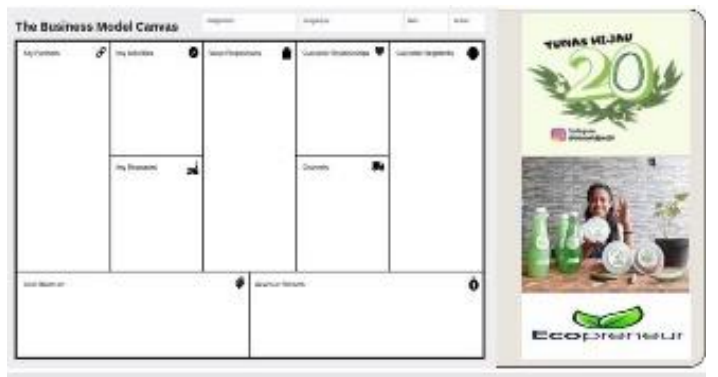

Gambar 6. Materi BMC

Mitra juga diberikan mentoring dalam penentuan visi dan misi serta struktur organisasi inkubator bisnis yang akan dibentuk. Hasil dari pendampingan ini nantinya mitra sudah memiliki rencana pembelajaran dan SOP (Standard Operational Procedure) untuk memulai menjalankan tugas sebagai inkubator yang akan membantu mengembangkan bisnis ecopreneur di sekolah.

Pendampingan juga dilakukan saat proses penyemaian dan pembibitan tanaman Okra. Biji Okra yang telah disortir direndam dalam air selama satu hari kemudian ditanam dalam tempat atau wadah yang datar dengan campuran tanah dan kompos 1:1. Setelah lima hari, biji Okra akan tumbuh daun dan akar. Kemudian dapat dilakukan pemindahan ke dalam baglog kecil untuk dijadikan bibit Okra. Bibit Okra dapat ditanam dalam baglog yang lebih besar atau dalam media tanah secara langsung dengan jarak tanam 60-100 cm.

Gambar 7 dan Gambar 8 menunjukkan kegiatan pendampingan pada penyemaian dan pembibitan tanaman Okra.

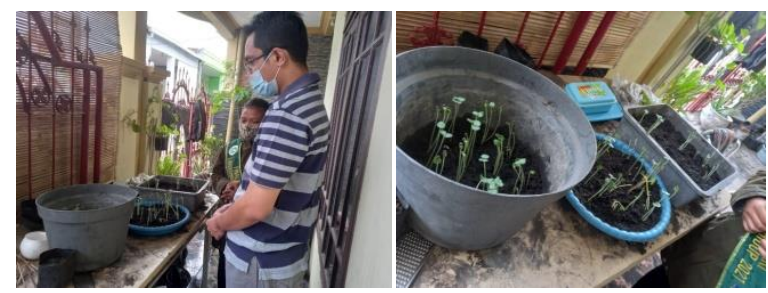


Gambar 7. Kegiatan penyemaian Okra

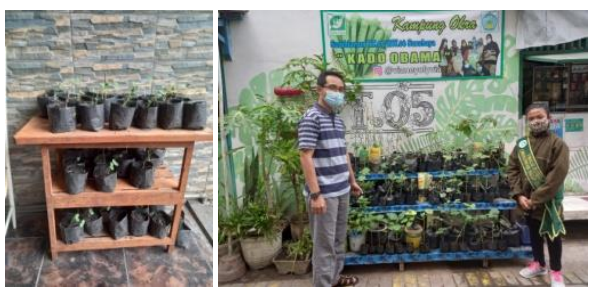

Gambar 8. Hasil pembibitan Okra

Selain hasil olahan Okra, biji dan bibit Okra dapat dijual secara langsung. Media pemasaran dilakukan melalui media sosial diantaranya dengan Instagram (IG) dan toko online Shopee (Gambar 9). Pudding Okra menjadi olahan yang paling disukai saat ini dan telah banyak peminatnya.

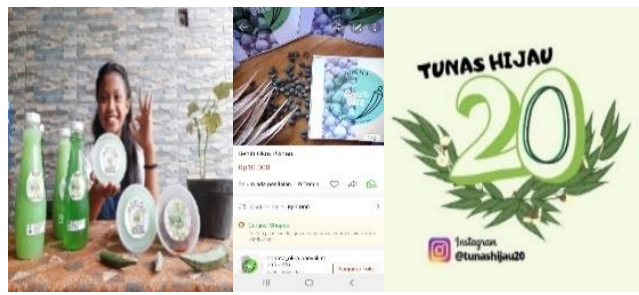

Gambar 9. Media pemasaran Okra dan kegiatan dalam IG

Pendampingan pada mitra dilakukan selama masa pengabdian dan sampai mitra mampu untuk mandiri. Metode pendampingan bisa dilakukan secara onsite atau offsite menyesuaikan dengan situasi pandemi dan regulasi yang ada.

\section{Evaluasi dan tindakan perbaikan.}

Program pengabdian ini dijalankan sesuai dengan tahapan dan metode yang telah direncanakan. Namun pada pelaksanaannya, terdapat hambatan yang membutuhkan analisis dan tindakan perbaikan. Kendala utama adalah adanya PPKM yang diperpanjang sehingga berdampak pada pertemuan dengan mitra. Pelatihan yang dilakukan belum dapat dilakukan dengan maksimal. Namun tim pengabdian dan mitra sepakat untuk terus menjalankan kerjasama dalam menyelesaikan program yang telah direncanakan.

Sebagai organisasi baru di sekolah, inkubator bisnis Tunas Hijau yang dibentuk perlu mendapat dukungan dari pihak sekolah. Manajemen dalam inkubator harus mempunyai program-program yang berkelanjutan. Pembina dan anggota dalam struktur manajemen inkubator harus memahami dan menjalankan Job Description dengan baik. Disamping itu, perlu upaya untuk melakukan kolaborasi dengan pihak ketiga agar dapat menciptakan tenant-tenant yang siap untuk mendapatkan pembinaan dan pengembangan. Mitra Tunas Hijau harus terus melakukan inovasi produk berbasis tanaman okra. Produk berikutnya yang akan menjadi kerjasama dengan tim pengabdian adalah produk minyak dan kopi okra (Gambar 10).

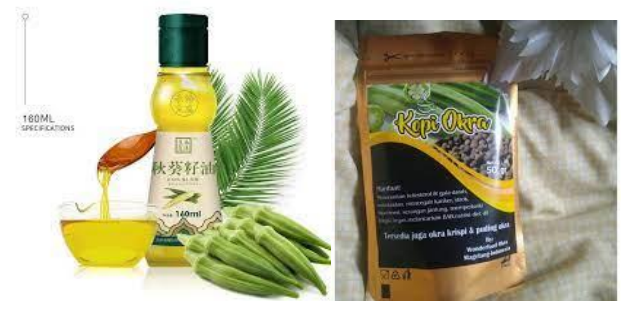

Gambar 10. Rencana inovasi produk baru minyak dan kopi Okra.

\section{KESIMPULAN}

Program pemberdayaan masyarakat pada mitra dilakukan selama masa pengabdian dan sampai mitra mampu untuk menjalankan programnya secara mandiri. Untuk permasalahan produksi, mitra sudah memiliki greenhouse untuk tempat penyemaian dan pembibitan tanaman Okra. Mitra juga sudah mempunyai produk unggulan yang mampu bersaing yaitu Pudding Okra. Selain itu, mitra juga dapat melayani permintaan berupa biji dan bibit Okra yang siap tanam. Pada permasalahan manajemen, pembina telah mempunyai sebuah model bisnis dan organisasi inkubator yang akan dapat memberikan pembinaan dan pengembangan kemampuan ecopreneur pada siswa. Sebagai inkubator bisnis yang baru, Tunas Hijau perlu melakukan kolaborasi dengan pihak lain 
untuk mendapatkan dukungan dan solusi dari permasalahan yang muncul nantinya. Tantangan yang dihadapi oleh mitra ke depan adalah bagaimana melakukan inovasi produk secara terus menerus dan mencari kader-kader yang dapat melanjutkan misi organisasi Tunas Hijau.

\section{UCAPAN TERIMAKASIH}

Ucapan terimakasih disampaikan kepada Lembaga Penelitian dan Pengabdian Masyarakat

\section{REFERENSI}

Administrator. (2017, April 10). cara mengolah okra menjadi obat diabetes. Retrieved from bapelkesjabar.diklat.id:

https://bapelkesjabar.diklat.id/caramengolah-okra-menjadi-obat-diabetes

Administrator. (2020, November 25). budidaya okra dalam pot polybag. Retrieved from cybex.petanian.go.id:

http://cybex.pertanian.go.id/artikel/95814/b udidaya-okra-dalam-pot-polybag

Administrator. (2020, October 26). teknik penanaman okra serta teknik dan metode pengelolaan lapangan. Retrieved from aiteknologi.com:

http://aiteknologi.com/teknik-penanamanokra-serta-teknik-dan-metode-pengelolaanlapangan

Aziz, K. A., Wulandari, S., \& Sagita, B. H. (2018). Perancangan Model Bisnis UKM Atelier Prana dengan Menggunakan Pendekatan Business Model Canvas. e-proceeding of engineering (p. 6828). Jogjakarta: Universitas Telkom.

Barus, R. A. (2016). Respon Pertumbuhan dan Produksi Dua Varietas Okra (Abelmoschus esculantus L. Moench) Terhadap
Universitas Wijaya Putra yang telah memberikan kontribusi dalam pelaksanaan kegiatan. Serta kepada Pembina Tunas Hijau, Guru dan Siswa SMPN 20 Surabaya yang telah bersedia menjalin kerjasama untuk pengembangan ecopreneur berbasis tanaman Okra.

Pemberian Berbagai Jenis Pupuk Organik. Medan: Universitas Sumatera Utara.

Fa'izah, A. Z. (2020, September 23). 7 cara mengolah okra menjadi sajian lezat mudah dan enggak ribet. Retrieved from merdeka.com:

https://www.merdeka.com/trending/7-caramengolah-okra-menjadi-sajian-lezatmudah-dan-enggak-ribet-kln.html?page=all

Gustiawan, Herawati, N., \& Noverta, A. (2018). Morfo-Agronomis Berbagai Varietas Okra Introduksi dan Evaluasi Hasil Persilangan dengan Kultivar Okra Hijau. Padang: Universitas Andalas.

Ikrawati, \& Rokhmah, N. A. (2016). Budidaya Okra dan Kelor dalam Pot. Jakarta: Balai Pengkajian Teknologi Pertanian (BPTP).

Mayasari, V., Liliana, \& Seto, A. A. (2019). Dampak Inkubator Bisnis Terhadap Minat Berwirausaha Mahasiswa di Universitas Tridinanti Palembang. JBKM (Jurnal Konsep Bisnis dan Manajemen) , 13-23.

Simanjuntak, R. D., \& Gultom, T. (2018). Pertumbuhan Tanaman Okra Hijau (abelmoschus esculentus L) di KP Balitsa, Tongkoh Barastiga. Seminar Nasional Biologi dan Pembelajarannya (pp. 1-10). Medan: Universitas Negeri Medan. 